\title{
EL SENTIDO COMÚN CRÍTICO ANTE EL DEBATE ENTRE UNIVERSALISMO Y PARTICULARISMO
}

\author{
H. C. F. Mansilla*
}

RESUMEN: El debate entre universalismo y particularismo ha sido importante y sigue siendo vigente en cuanto incide sobre los conceptos de identidad colectiva y nacionalismo, entre otros, cuyo impacto se traduce en posturas irracionastas y posmodernistas. El sentido común crítico, forjado en la tolerancia y la compresión del otro, se perfila como una solución posible.

\section{yose}

ABSTRACT: The debate between universalism and particularism has been and remains important, since it influences concepts such as collective identity and nationalism, among others, and impacts on irrational and postmodern attitudes. The critical common sense, based on tolerance and understanding of others, appears as a feasible solution.

PALABRAS CLAVE: Universalismo, particularismo, crítica, síntesis, tolerancia, posmodernismo. KEYWORDS: Universalism, Particularism, criticism, summary, tolerance, Postmodernism.

RECEPCIÓN: 18 denoviembre de 2008.

APROBACIÓN: 11 de junio de 2009.

*Academia de Ciencias de Bolivia. 
CITAM Derechos Reservados.

La reproducción total o parcial de este artículo se podrá hacer si el ITAM otorga la autorización previamente por escrito. 


\section{EL SENTIDO COMÚN CRÍTICO ANTE EL DEBATE ENTRE UNIVERSALISMO Y PARTICULARISMO}

La controversia entre particularismo y universalismo es un buen ejercicio para ver el funcionamiento de un sentido común guiado críticamente. Este debate, que ya tiene algunas décadas de duración, ha sido importante para comprender: (a) los dilemas centrales de las identidades colectivas; (b) el trasfondo del resurgimiento nacionalista en dilatadas regiones del planeta; $\mathrm{y}$, (c) la propagación de un marcado sesgo antirracionalista y postmodernista entre los intelectuales de Asia, África y América Latina.

\section{Crítica de las concepciones universalistas}

La declinación actual del marxismo y de las grandes teorías de carácter universalista, así como la devaluación de la filosofía unitaria de la historia y, en general, de toda forma del racionalismo clásico, han fomentado el surgimiento de concepciones particularistas, el renacimiento de doctrinas nacionalistas y la reaparición de creencias religiosas fundamentalistas. Las últimas décadas del siglo XX y el comienzo del XXI desmintieron aquella profunda convicción de marxistas y liberales que predecía la desaparición de la religión y del nacionalismo como resultado natural del progreso material y moral. Todo esto coincide, además, con algunos factores propios de la evolución contemporánea en Asia, África y Amé- 
rica Latina. La irrupción del proceso modernizador, en pocas décadas, ha generado un verdadero derrumbe de arraigadas ideologías y la conmoción del orden tradicional, por efecto de la exitosa cultura occidental del consumismo masivo. Estos factores y el descalabro general (pero no definitivo) del socialismo han suscitado en el Tercer Mundo -y no sólo allí-un vacío de valores de orientación. Esta constelación favorece iniciativas violentas y caóticas y la expansión de una anomia muy expandida. ${ }^{1}$ Se acrecienta, por un lado, la tentación del encierro en sí mismo, pero igualmente la inclinación a combatir lo Otro, presunta encarnación del mal y de las propias dificultades. El hallar a los chivos expiatorios no es, entonces, tarea difícil. Se trata, por otra parte, de un fenómeno repetido a lo largo de todo el curso de la historia humana.

Lo novedoso de la situación en el Tercer Mundo parece residir en una curiosa amalgama entre una defensa de la propia tradición cultural (percibida en estado de máximo peligro) y una apropiación acrítica de los elementos técnico-económicos de la civilización industrial de Occidente. No pocos socialistas y revolucionarios, que se quedaron sin trabajo y sin ideas, se dedican ahora a fomentar inclinaciones particularistas de toda laya y designios reivindicatorios de minorías étnicas, junto con los nacionalismos más delirantes, como ha ocurrido en los Balcanes, el Cáucaso, el África central y en el área andina de América Latina.

Ahora bien: desde un sentido común guiado críticamente, se puede decir que lo complejo de la problemática actual consiste en que a las minorías de todo tipo les asiste un cierto derecho. La doctrina del progreso perpetuo devalúa, por ejemplo, la calidad y los logros intrínsecos de etapas históricas anteriores, que son consideradas como meros eslabones de una evolución regida aparentemente por leyes inquebrantables, evolución que conduce necesariamente a una meta común a todas las culturas. Esto presupone un solo criterio para juzgar toda actividad

${ }^{1}$ Sobre la anomia como signo del tiempo actual, cfr. dos interesantes investigaciones: Carlos S. Nino, Un país al margen de la ley. Estudio de la anomia como componente del subdesarrollo argentino, 1992, Buenos Aires, passim; Peter Waldmann, El Estado anómico. Derecho, seguridad pública y vida cotidiana en América Latina, 2006, Madrid/Frankfurt, Iberoamericana/Vervuert, pp. 13-20. 
humana. Aunque los elementos racionales y razonables de esta concepción universalista están por encima de toda duda, la misma no favorece una perspectiva flexible que permita reconocer lo valioso del arte, la literatura, la religión y las costumbres de sistemas socioculturales que hoy nos parecen anacrónicos, insólitos o chocantes.

En una época de fronteras permeables, de un sistema global integrado de comunicaciones y de pautas normativas universales, nace la voluntad de oponerse a las corrientes de uniformamiento y despersonalización. Minorías étnico-culturales significan, a veces, un dique contra la homogeneización del mundo moderno, si combaten igualmente la dilución de tradiciones que han dado sentido a comunidades estables, donde la anonimidad y la alienación no son aún las características decisivas. Pero hay que señalar que también las minorías perseguidas pretenden alcanzar, después de todo, objetivos muy humanos, entre los cuales se hallan cálculos egoístas de expansión y dominación, incremento de sus beneficios tangibles y la explotación de otros segmentos poblacionales que entonces devienen minorías. La etnias originales del bosque amazonico van a ser seguramente exterminadas por otros aborígenes (por ejemplo, por los campesinos indígenas sin tierra, que emigran desde las empobrecidas y sobrepobladas regiones montañosas andinas), que tienen como objetivos la extensión de la frontera agrícola, la incorporación de esos territorios al progreso material, el aprovechamiento de nuevos recursos y la mera supervivencia individual.

La legítima aspiración de afirmar la propia identidad sociocultural puede, sin embargo, transformarse rápidamente en una tendencia xenófoba, racista, agresiva, demagógica y claramente irracional, que a la postre pretende la aniquilación del Otro y de los otros. "Esta actitud entraña una negación de los valores universales, un menosprecio de los derechos y libertades de la persona, un repudio a todo diálogo y a todo esfuerzo de educación para la tolerancia". ${ }^{2}$ Aquí lo razonable parece

${ }^{2}$ Federico Mayor, "Editorial”, en El correo de la UNESCO, junio de 1993, París, vol. XLVI, p. 9 (número monográfico dedicado a las minorías). Cfr. también las visiones diferentes: Elizabeth Picard, "El despertar de la comunidad", en El correo de la UNESCO, junio de 1993, vol. XLVI, pp. 22; el brillante ensayo de Mauro Peressini, "Las dos caras de la identidad", en ibidem, pp. 14-8; Joseph Ki-Zerbo, "Lo universal y lo particular", en El correo de la UNESCO, diciembre de 1993, vol. XLVI, pp. 1-20; Régis Debray, “¿De qué progreso hablamos? Un mito occidental”, en ibidem, pp. 9-12. 
ser una posición equidistante entre el universalismo doctrinario y los particularismos irracionales, aunque esta posición deba ser modificada y calibrada según cada caso, para lo que no existe una regla general, sino el principio de la prudencia y la plausibilidad (phronesis).

Para no repetir los rasgos principales de este debate, ya muy conocido, parece conveniente referirse a algunos aspectos concretos del mismo. En el Tercer Mundo se extiende ahora la opinión de que los derechos humanos, la filosofía racionalista, la ética del respeto liminar al individuo y las instituciones de la democracia representativa pluralista conformarían parte integrante de una inaceptable doctrina universalista, la que, a su vez, sería una forma encubierta de eurocentrismo y, por consiguiente, un instrumento de dominación cultural. No hay duda de que porciones centrales de esta magna concepción se han originado en el Occidente europeo y que a menudo han sido utilizados para justificar y consolidar un predominio imperial. Las facultades - o, si se quiere, las pretensiones- universalistas del racionalismo europeo no han sido, empero, los factores causales de procesos como la trata de esclavos, el saqueo de los recursos naturales y el exterminio de lo aborígenes, los que han tenido una historia más antigua y un alcance geográfico más dilatado que la moderna civilización europea occidental. Es claro que toda teoría con aspiraciones de generalidad y obligatoriedad concita reacciones hostiles. Por ello, la ética del derecho universal, como la contenida en la concepción contemporánea de los derechos humanos, es considerada como una máscara del imperialismo eurocentrista y, simultáneamente, como un solapado y peligroso ataque a las propias tradiciones autóctonas, las que a menudo exhiben prácticas consuetudinarias que no son congruentes con los derechos humanos y las libertades individuales. Las tendencias postmodernistas han impugnado igualmente la validez de una ética universal en nombre de la pluralidad e inconmensurabilidad de las otras culturas; ${ }^{3}$ ya que toda moral se fundaría sobre una base contingente y aleatoria, todo consenso ético reinante en una sociedad y época dadas es tan valioso o tan execrable como cualquier

${ }^{3}$ Cfr. el interesante teorema de David E. Apter, Rethinking Development. Modernization, Dependency and Postmodern Politics, 1988, Newbury Park, Sage. 
otro. Una moral universal, que trascienda los particularismos, sería imposible y hasta indeseable, pues refrenaría el libre despliegue de individuos y comunidades.

\section{Crítica de posiciones unilaterales}

Una visión realista y sobria de la historia de las naciones nos permite detectar las falacias y los peligros de aquellas corrientes que se consagran unilateralmente al universalismo o al particularismo. El rechazo del universalismo a causa de su presunto carácter eurocéntrico o su talante imperialista se combina con la búsqueda de una identidad cultural o nacional primigenia, que estaría en peligro de desaparecer ante el avasallamiento de la moderna cultura occidental de cuño globalizador. Esta indagación, a veces dramática y a menudo dolorosa para las comunidades afectadas, intenta desvelar y reconstruir una esencia étnica, cultural, lingüística o histórica que confiera características indelebles $\mathrm{y}$, al mismo tiempo, originales a la nación o al grupo social que se siente amenazado por la exitosa civilización moderna. Este esfuerzo puede ser calificado de inútil en casi todos los casos: los ingredientes aparentemente más sólidos y los factores más sagrados del acervo cultural e histórico de un pueblo resultan ser una mixtura deleznable y contingente de elementos que provienen que otras tradiciones nacionales o que tienen una procedencia común con los más diversos procesos civilizatorios. La quintaesencia identificatoria nacional o grupal, reputada como algo primordial, básico e inalterable, sólo puede ser definida y comprendida con respecto a lo complejo, múltiple y cambiante que está encarnado en lo Otro, es decir, en los elementos determinantes de las culturas ajenas y hasta hostiles. La alteridad es consubstancial a casi todo grupo social, y más aún, en el mundo actual. Este ejercicio de la búsqueda por lo auténtico y propio tiene efectos traumáticos porque pone de relieve aquella porción ínfima que tal vez puede ser considerada efectivamente como perteneciente al núcleo de la identidad incontaminada. Pero es simultáneamente una ocupación que goza del favor popular porque en las capas más profundas de la consciencia individual y colectiva se halla 
el propósito perseverante de aprehender y consolidar algo estable que dé sentido a las otras actividades humanas y que pueda ser percibido como el alma inmutable y positiva de la comunidad donde se vive y se sufre.

Es muy difícil encontrar un pueblo que haya pervivido hasta hoy conservando exclusivamente sus características originales de identidad, como las étnicas y lingüísticas, sin haber aceptado y adoptado, como propios, importantes elementos culturales de las naciones vecinas... y de las enemigas. Los aspectos más íntimos de las tradiciones civilizatorias pueden ser de data reciente o simplemente tomados "de afuera" y legimitizados como propios por la perseverante labor de todos aquellos dedicados profesionalmente a estas labores: magos y taumaturgos, intelectuales y políticos. La repetición constante de ciertas doctrinas puede crear, en poco tiempo, una tradición tenida como auténtica, lo que revela la índole precaria y contingente de numerosas identidades étnico-culturales. ${ }^{4}$ La concepción de un conjunto social cerrado, homogéneo y singular es, a menudo, un acto arbitrario de intelectuales descontentos que inventan un medio de simplificar $y$, por consiguiente, de comprender una realidad demasiado compleja. Lengua, raza y religión - consideradas habitualmente como esencias inmutables de la identidad colectiva e impermeables al transcurso del tiempo-constituyen los factores más usuales de esta ideología fundadora, consagrada a menudo a reinventar un pasado mítico, no contaminado por las influencias de "los otros". ${ }^{5}$ La llamada identidad nacional puede comenzar por ser un instrumento de un grupo minoritario para hacer frente a la opresión y la explotación, pero puede transformarse con el correr del tiempo en una ideología hermética, replegada sobre sí misma, proclive a la violencia xenófoba.

${ }^{4} \mathrm{Cfr}$., los estudios que no han perdido vigencia de Honorio M. Velasco, "Identidad cultural y política”, en Revista de Estudios Políticos, octubre/diciembre de 1992, Madrid, núm. 78, p. 257, 268 sq. (con ejemplos de la investigación antropológica actual); Rainer Tetzlaff, "La etnicidad politizada. Una realidad del África postcolonial”, en Nueva Sociedad, enero/febrero de 1994, Caracas, núm. 129, p. 47, 49.

${ }^{5}$ Cfr. el estudio clásico de Eric J. Hobsbawm/Terence Ranger (comps.), La invención de la tradición, 2002, Barcelona, Crítica. 
La historia universal puede ser vista como una serie interminable de fenómenos de mestizaje y aculturación; además de las innumerables mezclas étnicas, se ha dado igual cantidad de procesos, mediante los cuales, una sociedad recibe la influencia de una cultura que le es militar, técnica y organizativamente superior, siendo la consecuencia una simbiosis entre los elementos tradicionales y los tomados de la civilización triunfante. Cultura significa también cambio, contacto con lo foráneo, comprensión de lo extraño (como ya lo postuló Michel de Montaigne). El mestizaje puede ser obviamente traumático, pero también enriquecedor. ${ }^{6}$ Se podría aseverar que las sociedades más exitosas, como las de Europa Occidental, han sido aquellas que han experimentado un número relativamente elevado de procesos de aculturación, y que los individuos más aptos son los que tienen una multiplicidad de roles. El tratar de volver a una identidad previa a toda transculturación es, por lo tanto, un esfuerzo vano, anacrónico y hasta irracional: se puede pasar rápidamente de las reivindicaciones anti-imperialistas a las obsesiones nacionalistas y a los monstruosos ensayos de limpieza étnica por la fuerza de las armas.

En este ejercicio de sentido común se percibe que tanto los partidarios de doctrinas universalistas como los afines al particularismo tienen parcialmente la razón. Aquí, lo más conveniente parece ser una posición equidistante entre ambos extremos, algo que ha tratado de establecer Sir Isaiah Berlin precisamente en torno a esta temática. En su recapitulación de la historia de las ideas, se nota rápidamente que las críticas y contracríticas de esta discusión se deben a las falencias teóricas de posiciones claramente alineadas con el particularismo o el universalismo, sobre todo cuando éstas son confrontadas con la realidad histórica y la praxis política cotidiana. ${ }^{7}$

${ }^{6}$ Sobre el proceso de mestizaje, cfr. las obras aun hoy interesantes de Roger Bastide, El prójimo y el extraño. El encuentro de las civilizaciones, 1973, Buenos Aires, Amorrortu; Tzvetan Todorov, La conquête de l'Amérique. La question de l'Autre, París, Seuil, 1982; Nathan Wachtel, Los indios del Perú frente a la conquista española, 1976, Madrid, Alianza.

${ }^{7}$ Sobre la vida y la obra de este autor, cfr. Michael Ignatieff, Isaiah Berlin, una vida, 1999, Madrid, Taurus/Santillana; Claude J. Galipeau, Isaiah Berlin 's Liberalism, 1994, Oxford/New York, Oxford U. P. 
Los críticos del universalismo afirman, por ejemplo, que la comprensión de los decursos evolutivos en el Tercer Mundo y de sus identidades colectivas exige un punto de vista que supere las limitaciones y las falsas generalizaciones de la filosofía de la historia basada en el progreso perenne y de las teorías simplistas de la modernización. No es superfluo señalar aquí que la doctrina afín a una historia unitaria del género humano (con su correlato de una evolución histórica linear y ascendente) es favorable a un despotismo ilustrado, ejercido desde un centro omnímodo y omnisciente, que tiene la obligación moral e histórica de imponer su certeza y su proyecto al resto de la sociedad. Concordante con esta visión tecnocrática, un gran ilustrado, como fue el Marqués de Condorcet, combatió los llamados poderes intermedios que preconizó Montesquieu, el contrapeso mutuo de los poderes del Estado que patronizaban los liberales, toda forma de federalismo y hasta toda diferencia substancial entre ciencias naturales y sociales. El peligro inherente a esta concepción radica, como hoy se sabe, en la posibilidad de que el progreso continuo, las normas uniformantes y las grandes estructuras supranacionales se transformen en verdades irrefutables y en estrategias infalibles, es decir en abstracciones e idolatrías, ante cuyo altar se sacrifican los valores particulares y se aplastan las diferencias nacionales, para no mencionar a los millones de víctimas de carne y hueso que en el siglo XX fueron inmolados en nombre de esas doctrinas universalistas.

\section{La complementariedad de universalismo y particularismo}

La ética universalista y el derecho a la diferencia no son, sin embargo, nociones antagónicas, sino complementarias. La primera puede ser vista como la garantía del segundo: el derecho a la vida de personas y minorías puede ser protegido eficazmente cuando las mayorías no las ven como criaturas tan distintas de ellas mismas, que resultan proclives a ser confundidas con meras bestias o con esclavos. ${ }^{8}$ La ética del consenso

\footnotetext{
${ }^{8}$ Karl-Otto Apel, "Un imperativo moral”, en El correo de la UNESCO, vol. XLV, julio/ agosto de 1992, p. 16 sq.
} 
general, que no está basada en la intimidación o la manipulación, puede, mediante una comunicación más o menos libre en ambos sentidos, conciliar las normas universalistas y las demandas de una autorrealización individualizante, influida por tradiciones que se consideran estrictamente propias (es decir, auténticas). Criterios intersubjetivos universalmente válidos pueden coexistir con una pluralidad de postulados de índole particularista: una de las grandes metas del pensamiento humanista ha consistido, después de todo, en la creación de nociones, instrumentos y mecanismos para asegurar la paz general, respetando las peculiaridades de los diferentes pueblos e individuos. Todos procedemos de una tradición específica y estamos marcados por una cultura nacional. Tal hecho debe ser reconocido, pero no necesita ser idolatrado. El procedimiento que analiza y reconoce nuestros prejuicios y nuestras disparidades nos conduce también a la tolerancia y al respeto de los otros -lo que constituye el primer consenso universalista. De esta manera, uno se abre a la razón de los demás, en lugar de abrir a los demás por la fuerza a la razón de uno. Este principio general está alimentado por la tolerancia y el anhelo de comprender lo Otro. ${ }^{9}$ En el curso de la historia universal, lo más nefasto ha resultado ser la pretensión de poseer de modo exclusivo una razón obligatoria y superior (o sea, una presunción de índole universalista) partiendo de presupuestos particulares y hasta provincianos (esto es, sin percatarse del carácter limitado y limitante de los propios prejuicios).

El pensamiento "salvaje" y el erudito, la magia ${ }^{10}$ y la ciencia moderna son formas de un mismo logos humano. De acuerdo al relativismo axiológico, es un acto de soberbia establecer una jerarquía de calidades

${ }^{9}$ Alain Finkielkraut, La derrota del pensamiento, 1988, Barcelona, Anagrama, p. 41 sq., 61, 68 (con argumentos basados en Goethe y Lévi-Strauss). Una corriente en ciencias sociales considera que estos principios humanistas eran también parte fundamental del pensamiento clásico de la antigua China. Cfr. Joseph Needham, Dentro de los cuatro mares. Diálogo entre Oriente y Occidente, 1975, Madrid, Siglo XXI.

${ }^{10}$ Peter Winch, "Was heisst 'eine primitive Gesellschaft verstehen’?”(“¿Qué significa 'comprender una sociedad primitiva'?”), en Hans G. Kippenberg / Brigitte Luchesi (comps.), Magie. Die sozialwissenschaftliche Kontroverse über das Verstehen fremden Denkens (Magia. La controversia en ciencias sociales en torno a la comprensión del pensamiento foráneo), 1987, Frankfurt, Suhrkamp, p. 75 sq. 
entre ellas. Pero sería, por otra parte, un acto de simple necedad el no querer percibir las consecuencias tan diferentes de la magia (y prácticas afines) y la ciencia moderna, sobre todo en los campos de la política, la educación y la convivencia entre los mortales, pues los sistemas sociales basados o alimentados por creencias mágicas no se han distinguido justamente por una gran tolerancia cultural o por haber fomentado la vigencia de un pluralismo de ideas y predilecciones. La magia y la ciencia son ambas dependientes de un contexto cultural, social e histórico y, por ende, relativas. Pero reconocer esta relatividad ya trasciende el estrecho marco de un particularismo dogmático y avanza hacia un consenso universalista de tolerancia. El obscurantismo, que ha sido y es uno de los mayores males en nuestra sociedad interdependiente y globalizada, empieza y se define, como lo señaló Claude Lévi-Strauss, por "el rechazo ciego a lo que no es nuestro". ${ }^{11}$

En no pocas sociedades se ha visto que la diversidad étnico-cultural se transforma en un verdadero odio entre las comunidades en cuestión, que termina por destruir el tejido social que las envolvía y disolver el Estado correspondiente. Pero existen otras experiencias, también numerosas, que parecen sugerir la posibilidad de una sociedad estable en el tiempo, conformada precisamente por una pluralidad étnico-cultural dentro de un marco aceptado de instituciones y procedimientos políticos, el cual, además, irradia normas universalistas que permiten la convivencia de la comunidades y su florecimiento. Los Estados Unidos, a pesar de sus enormes problemas internos, configuran una estructura de ese tipo, cuya unicidad permite el despliegue de un mosaico multicolor que no cesa de acrecentarse. Los sucesos europeos en los Balcanes a partir de 1989 (y los del período entre las dos guerras mundiales) nos muestran que los conflictos étnico-culturales de carácter violento no son una reliquia incómoda del pasado premoderno, sino probablemente fenómenos de carácter universal.

Por todo esto, es conveniente echar un vistazo a enfoques que establecen un claro contraste entre ciencias naturales y sociales. Una de las primeras concepciones de este tipo fue la elaborada en el siglo XVIII por

${ }^{11}$ Claude Lévi-Strauss, Tristes tropiques, 1955, Paris, Plon, p. 461. 
Giambattista Vico (1668-1744). Según este pensador, entender un proceso histórico requiere de un impulso intuitivo, identificatorio y creativo de parte del sujeto cognoscente; este esfuerzo empático representa una certidumbre comparable a la ganada por métodos empíricos y constituye un procedimiento tan respetable y seguro como el de las ciencias naturales y exactas, aunque no represente, como éstas, una actividad absolutamente objetiva. Ya que el Hombre "produce" la historia -en contraposición a los fenómenos naturales creados por Dios, cuya aprehensión es más problemática-, su intelecto la puede comprender adecuadamente si se adentra en ella y la reconstruye teóricamente. Según Vico, el método cartesiano de la duda sistemática no es aplicable a fenómenos que dependen del contexto de la comunicación intersubjetiva, del marco lingüístico, de testimonios históricos aceptados como ciertos por una comunidad ni del sentido común que una sociedad se otorga a sí misma. ${ }^{12}$

Por otra parte, los enfoques universalistas y armonicistas, que subordinan todo esfuerzo a una meta única o a una única concepción de verdad y justicia, son poco propensos a permitir visiones y actitudes pluralistas por el valor intrínseco de ellas mismas. Para Vico, cada período histórico se hallaba, en cambio, en igual distancia con respecto a Dios: es decir, que poseía una dignidad propia equivalente a cualquier otra época histórica y podía ser comprendida únicamente si reconstruimos con empatía sus formas sociales y sus creaciones artísticas. Esto significa que cada etapa elabora sus propios conceptos de justicia y libertad, dependientes, al menos parcialmente, del imaginario colectivo de la época. Estos ideales no son mejores o peores que los de otras culturas o de tiempos posteriores, sino diferentes, pero en cuanto creaciones humanas pueden ser reconstruidas por aquellos que pertenecen a otros ámbitos civilizatorios, ya que no poseen la impenetrabilidad de la naturaleza extra-humana. ${ }^{13}$

${ }^{12}$ Giambattista Vico, Die neue Wissenschaft über die gemeinschaftliche Natur der Völker (La nueva ciencia sobre el origen común de los pueblos) [1725/1744], 1966, Reinbek, Rowohlt, p. 51 sq., 234 sq., 241.

${ }^{13}$ Isaiah Berlin, Against the Current. Essays in the History of Ideas, 1980, Londres, Hogarth, pp. 101-3. 
No hay duda de que Vico es uno de los padres del pluralismo cultural moderno, como lo ha calificado Isaiah Berlin en brillantes ensayos. ${ }^{14}$ Según esta concepción, cada cultura auténtica posee sistemas inconfundibles de valores, que, pese a estar encubiertos por otros factores en el transcurso de la historia, nunca llegan a desaparecer del todo, lo que permite precisamente que generaciones posteriores los puedan reconstruir y comprender. La teoría de Vico tiene la ventaja de no caer en un relativismo extremo, ya que la facultad de entender y apreciar una cultura pretérita o ajena presupone una cierta unidad de las facultades cognoscitivas y valorativas de toda la humanidad. Este entendimiento imaginativo (empatía) nos permite una estimación más adecuada de los ritos, las cosmologías, las metáforas, la literatura y los mitos de sociedades muy alejadas de la nuestra: adentrándose en estas creaciones humanas, no sólo podemos describir exteriormente cómo funcionan éstas -lo que hacen habitualmente las ciencias naturales-, sino que podemos penetrar en las motivaciones primeras o últimas de sus autores y percatarnos que no se trata de productos de la barbarie "primitiva", del infantilismo histórico o de perturbaciones insignificantes debidas a artistas excéntricos, sino de elaboraciones humanas que bien pueden ser las nuestras. Vico propuso, basado en una idea aristotélica, una concepción del saber en cuanto la consciencia acumulativa de la experiencia humana: el Hombre llega a comprender su propio mundo y su presente si intuye adecuadamente las esperanzas, los temores y los anhelos que subyacen a las obras del pasado y de otros pueblos. Ya que sus motivaciones actuales están entretejidas inseparablemente con las de sus antecesores y las de los otros, sólo podrá conformar una sociedad digna de este nombre si logra entender y apreciar lo pretérito y lo Otro. Esta comprensión, que tiene fuertes rasgos hermenéuticos y que es usual en las ciencias histórico-sociales, es, sin duda, diferente de la explicación

${ }^{14}$ Isaiah Berlin, "The Divorce between the Sciences and the Humanitites", en Berlin, Against..., op. cit., pp. 80-110; Berlin, "Vico's Concept of Knowledge", en ibidem, pp. 111-9; Berlin, "Vico and the Enlightenment", en ibidem, pp. 120-9; Berlin, "Giambattista Vico und die Kulturgeschichte" ("Vico y la historia de la cultura"), en Berlin, Das krumme Holz der Humanität. Kapitel der Ideengeschichte (La madera torcida de la humanidad. Capitulos de la historia de las ideas), 1992, Frankfurt, Fischer, pp. 72-96. 
analítica de causas y efectos que prevalece en las ciencias naturales. Al penetrar en las culturas "ajenas", nos percatamos de sus diferencias fundamentales y del pluralismo axiológico, que es una de las características del mundo del Hombre; pero esta misma operación presupone la ya mencionada unidad de aptitudes cognoscitivas entre todos los seres humanos. Los principios normativos de los "otros" son de igual manera auténticos, aunque muchas veces se manifiesten como contrarios y excluyentes. Pero aun cuando no exista una concordancia última entre ellos, podemos darnos cuenta de sus fundamentos y su razón de ser y podemos, por lo tanto, comprender su función específica en el interior de su sociedad respectiva. ${ }^{15}$

\section{La crítica de los extremos}

En este contexto es útil examinar una posición que puede generar extremos insostenibles. Los pensadores postmodernistas defienden a ultranza los particularismos y relativismos socio-culturales porque éstos serían los resultados únicos e irreproducibles de un contexto histórico también insubstituible, original par excellence y, por lo tanto, inconmensurable según cualquier parámetro de comparación histórica o sociológica. Esta concepción, que se remonta, por medio de diversos canales, a Johann Gottfried Herder (1744-1803), rechaza todo juicio evaluativo acerca de los conjuntos socio-culturales y las etapas civilizatorias a causa de la unicidad, peculiaridad y singularidad de estos fenómenos. No se puede negar lo razonable de algunos elementos de esta doctrina, ya que las ideologías universalistas radicales -como el hegelianismo y el marxismo-se han consagrado largamente a vituperar las más diversas y nobles construcciones culturales e históricas del Hombre como meros estadios de pasado por el progreso y dignas, por ende, de desaparecer y ser integradas, sin más, dentro de las culturas y las naciones triunfantes. La autonomía y el abanico de posibilidades de desarrollo de cada

${ }^{15}$ Cfr. Berlin, "Der angebliche Relativismus des europäischen Denkens im 18. Jahrhundert" ("El presunto relativismo del pensamiento europeo en el siglo XVIII"), en Berlin, Das krumme..., op. cit., p. 103, 108 sq. 
pueblo se debían, según el joven Herder, a que cada cultura es autorreferencial y a que no existe una gradación progresiva de las mismas que permitiese la edificación de un continuum que vaya del atraso al progreso y que sea, por consiguiente, el criterio para juzgar la calidad evolutiva de cada cultura. ${ }^{16}$ Los postmodernistas se olvidan, sin embargo, de que el Herder maduro combinó esta concepción con la idea de una humanidad universal que englobara a todos los hombres y cuya normatividad racionalista fuese al mismo tiempo la meta de la naturaleza humana.

Las versiones del postmodernismo contemporáneo, que carecen del humanismo y del sentido de las proporciones de Herder, y sobre todo de Vico, se limitan a celebrar sin más el culto de lo existente en un momento dado, terminando casi inexorablemente en alabar tanto los aspectos rescatables como los censurables de una cultura dada. La apología de lo fáctico y lo casual, de lo que se ha desplegado históricamente así y no de otra manera, desemboca a menudo en el encomio de los "prejuicios útiles" (Joseph de Maistre), tan caros a los gobernantes. ${ }^{17}$ Este culto de lo contingente y lo dispar resulta ser también algo primordialmente conservador. Siguiendo este lineamiento, muchos pensadores afiliados al postmodernismo otorgan su aquiescencia a formas odiosas de opresión y vulneración de los derechos humanos, empleando el argumento de respetar escrupulosamente los valores nacionales y las tradiciones extra-europeas y de combatir la asimilación forzada de éstas a los cánones del "imperialismo" inmerso en la Ilustración y la razón de Occidente. "Nacido del combate en favor de la emancipación de los pueblos, el relativismo desemboca en el elogio de la servidumbre". ${ }^{18}$ Puesto que cada manifestación cultural vale lo mismo que cualquier otra, se llega a trivializar todas ellas. Esta postura trae consigo el fomento indirecto, pero efectivo, de una nueva barbarie, la promoción de un infantilismo civilizatorio, el rechazo de algunas conquistas nada desdeñables como el espíritu crítico, la duda y la ironía y, por consi-

${ }^{16}$ Berlin, "The Divorce...", op. cit., pp. 101-3.

${ }^{17} \mathrm{Cfr}$. Berlin, "Joseph de Maistre und die Ursprünge des Faschismus" ("Joseph de Maistre y los orígenes del fascismo"), en Berlin, Das krumme..., op. cit., pp. 123-221.

${ }^{18}$ Alain Finkielkraut, op. cit., p. 111. 
guiente, un impulso enérgico para modos refinados de intolerancia. Ante esta situación, no es arbitraria la idea de proteger a la gente contra los abusos, daños y absurdos que eventualmente proceden de su propia tradición socio-cultural.

La revalorización de los particularismos nacionales está asociada al romanticismo del siglo XIX y a ciertas doctrinas conservadoras e irracionalistas. Los románticos afirmaron que las grandes corrientes homogeneizadoras han aplastado la heterogeneidad de los pueblos y el pluralismo civilizatorio, destruyendo así el carácter de hogar familiar que habían tenido previamente las comunidades políticas desaparecidas. De acuerdo con Axel Honneth, uno de los méritos principales del romanticismo consistió en descubrir el valor ético de la pertenencia cultural de cada individuo y grupo, lo que conformaría un adecuado polo contrario al frío "racionalismo monista" de la Ilustración clásica. ${ }^{19}$

Los valores universalistas de origen europeo (como la primera Declaración de los Derechos Humanos de 1789) han abierto paradójica e inesperadamente las compuertas para toda una serie de derechos grupales, sociales, económicos y nacionales. Los ideales de la Ilustración y el racionalismo afirmaron radicalmente la autonomía individual, liberando a cada persona de adscripciones heterónomas, definitivas, atávicas e irracionales, colocado al individuo y a sus derechos innatos por encima del Estado, la tradición y los colectivos de todo tipo. Esta es una conquista irrenunciable de la humanidad. Hoy en día, empero, una fuerte corriente de pensamiento y acción contrapone los derechos humanos de corte universalista e individualista a las normas culturales, los valores tradicionales y los derechos colectivos de grupos, comunidades y naciones, porque éstos encarnarían lo propio y auténtico de pueblos que no quieren sucumbir al imperialismo cultural de Occidente. Aquí es imprescindible llamar la atención sobre la dignidad superior de los derechos del Hombre como los ha codificado paulatinamente la herencia de la Ilustración; los derechos políticos, el Estado de Derecho y el

${ }^{19} \mathrm{Cfr}$. la notable obra de Axel Honneth, Das Andere der Gerechtigkeit. Aufsätze zur praktische Philosophie (Lo otro de la justicia. Ensayos sobre filosofia práctica), 2000, Frankfurt, Suhrkamp, p. 311. 
pluralismo democrático pertenecen igualmente a aquel amplio conjunto de principios éticos universales, cuya validez precede a cualesquiera particularismos nacionales, por más populares que éstos resultaran ser. El racismo, el asesinato (por cualquier causa), el canibalismo, el homicidio ritual y toda otra transgresión a los derechos humanos no pueden ser tolerados de ninguna manera.

Esta tensión entre universalismo y particularismo se manifestó a lo largo de la Conferencia de las Naciones Unidas sobre Derechos Humanos, que tuvo lugar en Viena en junio de 1993. La República Popular de China, algunos países africanos y asiáticos y, muy especialmente, las delegaciones de los estados del ámbito islámico, se opusieron a la universalidad de los derechos humanos que atañen al individuo, creyendo ver en ella una imposición de las naciones occidentales. Es sintomático el hecho, empero, de que estos países estén gobernados por dictaduras o, por lo menos, por regímenes bastante autoritarios; la condenación de los derechos humanos en cuanto extraños a su propio patrimonio cultural ha sido y es una maniobra transparente para encubrir violaciones de los derechos ciudadanos, cometidas por agentes e instituciones de gobiernos, cuya legitimidad democrática es dudosa. La insistencia en que los derechos colectivos, avalados por las tradiciones nacionales, deberían tener prevalencia sobre los derechos individuales, constituye una clásica ideología, es decir, un ensayo para justificar hechos y decursos evolutivos que serían condenables a la luz de la razón y de un common sense guiado críticamente. Las dictaduras pedagógicas que intentan una industrialización forzada, los experimentos socialistas de corte marxista y los sistemas sociales arcaicos sometidos al fundamentalismo islámico recurren, ahora, en una curiosa unanimidad, al relativismo cultura ${ }^{20}$ para racionalizar prácticas muy convencionales de opresión, explotación

${ }^{20}$ Un ejemplo de este relativismo cultural de carácter apologético: Manzoor Ahmad, "Islamic Response to Contemporary Western Thought", en Zeitschrift Für Kulturaustausch, octubre/diciembre de 1992, Stuttgart, vol. 42, núm. 4, pp. 426-34. Cfr. una crítica: Ulrich Greiner, "Wider den Kulturrelativismus" ("Contra el relativismo cultural"), en Die Zeit, del 5 de junio de 1992, Hamburgo, y el número monográfico de "Zeitschrift Für Kulturaustausch", enero/ marzo de 2002, vol. 52. El relativismo cultural se sirve de una tolerancia excesiva con respecto a los fenómenos de autoritarismo y represión, pervirtiendo, por consiguiente, un principio de la Ilustración y del racionalismo. 
y manipulación de sus súbditos. Este enfático rechazo a los principios éticos occidentales es tanto menos digno de fe cuanto los mismos regímenes se sirven a manos llenas de la tecnología occidental en los campos de las armas, las comunicaciones y la industrialización.

Los fenómenos socio-políticos de la segunda mitad del siglo XX parecen mostrarnos que no hay duda de que el cosmopolitismo liberal a ultranza es vacío y que no logra concitar emociones sociales relevantes; la gente no puede desplegar plenamente sus facultades si no está enraizada en una tradición cultural viviente. Tan indispensable como la vivienda y la alimentación resultan ser la familiaridad con los lazos primarios (como el lenguaje y tradiciones histórico-culturales compartidas desde la niñez), la pertenencia a un grupo identificable y distinto de los demás y la comunicación espontánea con parientes y amigos. Sólo una comunidad primaria puede brindar la seguridad emocional y el reconocimiento primordial-exento del principio de rendimiento y desempeño- que evitan las formas extremas de enajenación, soledad, desarraigo y autodesprecio individuales. ${ }^{21}$ Los vínculos primarios y el legado de tradiciones vivientes tienen, por lo tanto, funciones positivas para el desarrollo de conciencias individuales sólidas y sin complejos de inferioridad, funciones que no pueden ser reemplazadas por abstracciones como la ética universalista, las obligaciones contractuales, las estructuras burocrático-administrativas y las organizaciones supranacionales, por más importantes y eficaces que también éstas sean.

Los peligros inherentes al particularismo son conocidos y ciertamente substanciales. Esta corriente puede exacerbar sentimientos nacionalistas y tendencias irracionalistas; puede contribuir a diluir las grandes contribuciones de la Ilustración y el racionalismo europeo; a aumentar las discrepancias entre los pueblos; a magnificar las diferencias entre los individuos, y a entorpecer el entendimiento entre sociedades y también entre los hombres. Valores particulares, en primera instancia, los nacionales, pierden fácilmente su característica de meras señas de identidad, iguales o, por lo menos, comparables a las de las otras naciones, y se

${ }^{21}$ Berlin, "The Counter-Enlightenment”, en Berlin, Against..., op. cit., pp. 10-4. 
transforman en cualidades sagradas, mejores y más respetables que las de los vecinos y de todos los otros pueblos. Simples peculiaridades identificatorias, sin las cuales no puede vivir ningún individuo y ninguna comunidad, se convierten en evidencias de la propia superioridad sobre los otros, superioridad que debe ser demostrada en los terrenos de la economía, la política y la guerra. La exaltación de lo propio y particular hace olvidar el origen común de todos los grupos humanos, sobre lo cual se basa todo humanismo religioso y secular; este ensalzamiento particularista permite percibir a cualquier persona y a pueblos enteros como desprovistos de características humanas, es decir, como seres inferiores que pueden ser utilizados y hasta asesinados sin remordimientos. Como Isaiah Berlin aseveró, las formas extremas de particularismo terminan en la barbarie. ${ }^{22}$

\section{Particularismo y autoritarismo}

La apología del particularismo desemboca a menudo en una impugnación de los derechos humanos y ciudadanos en cuanto la manifestación más ostensible del "imperialismo" cultural. Hay un paso de ahí a la defensa de formas convencionales de arbitrariedad, injusticia y explotación mediante el razonamiento de que se trata de modelos propios y peculiares, avalados por la tradición, de modos de vida ajenos a la civilización europea occidental. Uno de los argumentos particularistas más difundidos contra el universalismo consiste en contraponer la diversidad de las estrategias y los cálculos del instinto de autoconservación y supervivencia frente a la postulada unicidad de la naturaleza humana, señalando que la pluralidad de órdenes culturales y sociopolíticos, a través de la historia, no admite la suposición de una naturaleza unitaria y estable del Hombre. Contra estas aseveraciones se puede argüir que precisamente todas las manifestaciones del instinto de conservación pueden ser interpretadas como los resultados histórico-prácticos (muy dife-

\footnotetext{
${ }^{22}$ Berlin, "Die europäische Einheit und ihre Wechselfälle" ("La unidad europea y sus altibajos”), en Berlin, Das krumme..., op. cit., p. 228.
} 
rentes entre sí) de una misma fuerza primordial, que es el egoísmo humano.

La dialéctica de universalismo y particularismo está trabada con la identidad de naciones que quieren liberarse de la tutela de las grandes potencias coloniales. El rechazo de los valores y las metas universalistas es una típica actitud intelectual que emerge justo después de una relación extensa, ambigua y traumática con una cultura triunfante en los campos económico, tecnológico y político, y cuando una porción considerable de la propia población -empezando por la élites- adopta ostentosa e inequívocamente las pautas de orientación de las sociedades reputadas como superiores. A éstas se les atribuye precisamente el carácter de lo universal y lo avalado por el progreso histórico. Pero las capas y los grupos sociales, que no han sido los beneficiados por este proceso-y muy especialmente sus intérpretes intelectuales- perciben todo esto como una traición a la esencia peculiar de aquella nación en condiciones de inferioridad, como una defección de sus auténticas metas civilizatorias y como un abandono de sus tradiciones más sagradas. La reconquista de la identidad y de sus rasgos particulares resulta ser, a la postre, una ideología convencional, una racionalización de otra intención muy comprensible: el hacer pasar un modelo híbrido de desarrollo como si fuese la continuación o el renacimiento de un venerable legado histórico, soterrado momentáneamente por la agresión imperialista en connivencia con la reacción local. El régimen practicado o al cual se aspira bajo esta doctrina no es, obviamente, un simple retorno al pasado y a sus valores identificatorios particularistas. En todo el Tercer Mundo, estas culturas que se hallan a la defensiva pretenden una síntesis entre el desarrollo técnico-económico moderno y la civilización tradicional en los campos de la vida familiar, la religión y las estructuras socio-políticas. Es decir, aceptan de manera totalmente acrítica los últimos progresos de la tecnología, los armamentos, los sistemas de comunicación más refinados provenientes de Occidente y sus métodos de gerencia empresarial, por un lado, y preservan, por otro, de modo igualmente ingenuo, las modalidades de la esfera íntima, las pautas colectivas de comportamiento cotidiano y las instituciones políticas de la 
propia herencia histórica conformada antes del contacto con las potencias europeas.

A lo largo de la historia universal han existido muchos intentos de legitimizar estos regímenes híbridos y esta aceptación parcial y parcializante de la civilización occidental. Ya en la China de comienzos del siglo XIX se hacía una diferencia entre la religión, la cultura, la filosofía y la política de los "bárbaros" occidentales, por un lado, y sus técnicas militares e industriales, por otro. ${ }^{23}$ Lo primero debía ser rechazado tajantemente, pues era el núcleo de una sociedad aborrecible, pero lo segundo constituía lo "aprovechable" de la misma, que podía ser utilizado sin contaminar la identidad de la cultura endógena. El resultado es una modernidad imitativa, que adapta más o menos exitosamente algunos rasgos de la sociedad industrial moderna, rasgos que pueden ser resumidos bajo la categoría de una racionalidad instrumental. Pero sus otros grandes logros, que van desde la democracia parlamentaria hasta el racionalismo y la ética basada en el humanismo y la tolerancia, son escamoteados discretamente o rechazados con inusitada vehemencia, como en los casos del fundamentalismo islámico, de las dictaduras militares populistas del África subsahariana o en los variados experimentos del socialismo radical tercermundista.

La dialéctica entre particularismo y universalismo se presenta, entonces, como un fenómeno sumamente complejo. El relativismo extremo, que, como se sabe, propugna no sólo el carácter dependiente y condicionado de los juicios valorativos, sino también el de las afirmaciones sobre hechos empíricos y documentales, se enreda en contradicciones internas que lo hacen inservible para el trabajo crítico-analítico serio. Una posición equidistante entre relativismo y universalismo permite, en cambio, un pluralismo genuino que reconoce el pleno derecho de sistemas socio-culturales y político-institucionales a florecer simultánea o suce-

${ }^{23}$ Cfr. Rudolf G. Wagner, "Staatliches Machtmonopol und alternative Optionen. Zur Rolle der 'westlichen Barbaren' im China des 19. Jahrhunderts" (Monopolio estatal del poder y opciones alternativas. Sobre el rol de los 'bárbaros occidentales' en la China del siglo XIX”), en Jan-Heeren Grevemeyer (comp.), Traditionelle Gesellschaften und europäischer Kolonialismus (Sociedades tradicionales y colonialismo europeo), 1981, Frankfurt, Syndikat, p. 127,130 sq., 133. 
sivamente, y que admite una multiplicidad de metas normativas, doctrinas éticas y corrientes estéticas, que, sin embargo, pueden ser comprendidas, aunque no siempre justificadas, por un mismo esfuerzo intelectual. Los portadores de valores y convicciones diferentes pueden llegar a tener sentimientos altruistas para con el otro, a sostener racionalmente un diálogo y a enriquecer el propio acervo, entendiendo precisamente sus diferencias.

Aun cuando no existan códigos aceptados universalmente a través del tiempo y el espacio, se puede detectar un mínimo de preceptos recurrentes que constituye algo así como una base común de entendimiento mutuo, sin la cual no habría posibilidad de coexistencia alguna. El asesinato, el robo y la mentira, por ejemplo, aunque siempre han sido practicados extensamente, nunca han recibido una sanción legal o moral positiva. Por otra parte, los mortales buscamos habitualmente y en casi todos los contextos geográficos e históricos, como afirmó Isaiah Berlin, el reconocimiento del otro y no el desdén o la incomprensión; anhelamos, igualmente, calor humano en lugar del desafecto permanente y, sobre todo, acercarnos a lo que consideramos la verdad y no caer en los lazos del error y el engaño. ${ }^{24}$ Consideramos como fundamentales estos principios morales y valores de orientación, no porque hayan sido enunciados por nuestros antepasados con carácter mítico o divino, sino porque creemos ver en ellos la precondición para la convivencia-en un mundo pequeño y común- con otros individuos y otras sociedades. Estos principios conforman la base irrenunciable para que los otros nos reconozcan como humanos y nosotros a ellos. Es decir, no percibimos estos preceptos en cuanto manifestaciones particulares de una sociedad específica $\mathrm{y}$, por ende, como arbitrarias e indiferentes para nosotros, sino como normativas válidas en los contextos más diversos, porque nos ayudan a comprender a los extraños y a convivir con ellos. Su universalidad se deriva, entonces, de una actitud práctico-pragmática que ya ha dado resultados positivos, y no de un fundamento metafísico o teológico: nos servimos de ellos, dice Isaiah Berlin, cuando resistimos agresiones socia-

${ }^{24}$ Berlin, Die europäische..., op. cit., p. 257 sq. 
les o cuando nos oponemos a la destrucción de la libertad de parte de regímenes despóticos. ${ }^{25}$

El relativismo sostiene, en cambio, que una moral universal no sólo sería imposible, sino también indeseable: el universalismo sofocaría de modo "imperialista" la multiplicidad de las formas de vida, sus diferencias específicas y sus identidades autóctonas. El relativismo culturalista que se deriva de esta posición niega, por ejemplo, la posibilidad de establecer una separación tajante y clara entre totalitarismo y democracia. Evitando aparecer como "racistas" o "imperialistas", los partidarios del relativismo aceptan mutilaciones rituales, penas corporales u otras vulneraciones de los derechos humanos en cuanto manifestaciones de otros ámbitos civilizatorios que tenemos que consentir en el marco de una amplia indulgencia, ya que no poseemos principios obligatorios para juzgarlos. Se puede aseverar, sin embargo, que el relativismo cultural, en nombre de una aparente tolerancia propia, admite como legítima cualquier intolerancia ajena, con lo cual se destruye todo consenso entre pueblos e individuos. Un ejemplo: las desventajas, que están vinculadas con todo modelo social premoderno y con toda corriente particularista, son claramente perceptibles en el mundo islámico de hoy, desgarrado entre un legado autoritario y una modernización que socava los fundamentos de una identidad colectiva basada en una férrea unidad entre religión, política y vida social. Contra los ideólogos del particularismo islámico, se puede aducir que esta tradición propugna también la validez universal de sus principios, normas y valores de orientación $-\mathrm{y}$ de un modo bastante imperioso, cuando no despótico; que la historia de esta cultura está plagada de atropellos de todo tipo cometidos contra otros pueblos; y que la absoluta predominancia de la fe religiosa, que ha impregnado todo aspecto de la vida civil, no es favorable ni a un proceso más o menos autónomo de modernización ni a la comprensión de las otras comunidades (y, sobre todo, de sus singularidades) a nivel mundial.

Con el popular argumento de cimentar la unidad de la nación, cohesionar el cuerpo social y unir todas las energías en pro de un desarrollo

${ }^{25}$ Ibidem, p. 259. 
acelerado, los ideólogos de la liberación anti-imperialista han desempolvado ese legado indígena de colectivismo totalitario y lo han utilizado eficazmente para acallar toda crítica al gobierno nacionalista o progresista y, paradójicamente, para suprimir toda tendencia regionalista o étnico-cultural (es decir, eminentemente particularista). "Una nación", escribió Alain Finkielkraut, "cuya vocación primera consiste en aniquilar la individualidad de sus ciudadanos, no puede desembocar en un Estado de Derecho". ${ }^{27}$ Es curioso, pero en el fondo comprensible, que la mayoría de los llamados "movimientos de liberación nacional", así como las corrientes izquierdistas y revolucionarias en el Tercer Mundo hayan elegido en muchísimos casos el principio de la identidad étnico-cultural -conservador y hasta reaccionario- como fundamento de los nuevos Estados y no la noción liberal de la asociación voluntaria laica de los ciudadanos consultados previamente.

\section{La síntesis como respuesta contemporánea}

Contra la defensa intransigente de las identidades nacionales, las minorías étnicas y el "desarrollo orgánico" de una comunidad presuntamente única hay que servirse de un argumento central del relativismo y postmodernismo: identidades y tradiciones son productos aleatorios de la evolución humana; su núcleo identificatorio es una ilusión o, en el mejor de los casos, una convención; no pocas nacionalidades son inventos de grupos munidos de astucia y audacia. Las minorías que hoy protestan vehemente y violentamente por su autodeterminación han sido conglomerados socio-culturales que han convivido pacíficamente y sin llamar la atención a lo largo de siglos con los grupos étnicos de los cuales ahora quieren

${ }^{26}$ La literatura tercermundista consagrada a la "liberación nacional" contra el imperialismo está llena de teorías presuntamente progresistas que encubren una ideología arcaizante, colectivista, antidemocrática y profundamente irracional: tanto más retrógrada cuanto más revolucionaria aparece prima facie. Ejemplos de ello son los escritos de Fidel Castro y Ernesto Che Guevara; el fundamentalismo islámico de corte radical; y las reivindicaciones nacionalistas, que pretenden simultáneamente el cambio social total. La obra precursora de estas corrientes fue Frantz Fanon, Les damnés de la terre, 1961, París, Maspero, passim.

${ }^{27}$ Alain Finkielkraut, op. cit., p. 74. 
liberarse a toda costa. Su consciencia actual de minoría discriminada ha surgido de manera igualmente contingente: es decir, podría haber ocurrido -con el mismo derecho histórico-cualquier otra cosa. A la caída del Imperio Austro-húngaro (1918), las antiguas minorías de Europa Oriental se transformaron en etnias opresoras y su derecho a la autodeterminación ha entrado en contradicción con los derechos de otras comunidades minoritarias y con el ejercicio efectivo de la democracia. $^{28}$

No se debe, empero, confundir relativismo con pluralismo cultural. Este último es la constatación neutral y descriptiva de que hay una multiplicidad de sistemas culturales y modelos civilizatorios sobre la Tierra, cada uno con sus peculiaridades que - a menudo, pero no siempre- enriquecen el conjunto de la humanidad. El pluralismo reconoce como positiva esta variedad paralela de naciones y culturas, que pueden coexistir de manera pacífica, justamente porque aceptan algunas normas universalmente válidas, como los derechos humanos. Este tipo de pluralismo es tanto más necesario cuanto vivimos una era de "globalización estructural y fragmentación cultural”, como escribió Bassam Tibi: el progreso económico y técnico, unido a la difusión de los medios de comunicación, puede separar a las diferentes culturas y naciones y acrecen-

124 tar el odio entre ellas, precisamente al percatarse los seres humanos y los pueblos de cuán diferentes son entre sí. ${ }^{29}$

La ética universal, justamente en sus versiones mejor impregnadas del humanismo occidental, es proclive al despliegue de las diferencias individuales y particulares al haber asegurado la base teórica y los derechos prácticos que permiten efectivamente el florecimiento de la diversidad, ya que de otro modo, los sujetos particulares habrían acabado destruyéndose mutuamente entre sí en una guerra de todos contra todos, apoyándose en el derecho inalienable de la autorrealización y en la

${ }^{28} \mathrm{Cfr}$. René Lemarchand, "El espejismo de la autodeterminación”, en El correo de la UNESCO, junio de 1993, vol. XLVI, pp. 29-32; Andrés Serbin, "Globalifóbicos vs. globalitarios. Fortalezas y debilidades de una sociedad civil regional emergente", en Nueva sociedad, noviembre/diciembre de 2001, núm. 176, pp. 67-86.

${ }^{29}$ Bassam Tibi, Im Schatten Allahs. Der Islam und die Menschenrechte (Bajo la sombra de Alá. El Islam y los derechos humanos), 1996, Munich, Piper, p. 34 sq.; Ann E. Mayer, Islam and Human Rights. Tradition and Politics, Boulder, Westview, 1991. 
doctrina de la inconmensurabilidad de objetivos y valores. Una moral fundamentada en ciertos principios generales permitiría, en cambio, establecer una comunicación en ambas direcciones, por más precaria que ésta resultase, conciliando exigencias indispensables para la convivencia con los esfuerzos en pro de una desarrollo autónomo y propio, todo ello en el marco de un consenso racional que excluya la intimidación y la manipulación.

Es importante indicar que la actual corriente, fuertemente adversa a cualquier universalismo (la "tiranía de lo general", según Jean-François Lyotard), parte de una equivocación liminar: confundir universalidad con uniformidad o, más concretamente, la validez de principios de derecho general con un impulso de aplastar las diferencias sociales y culturales. Precisamente porque las condiciones del surgimiento de regímenes, instituciones, normas y costumbres son contingentes y aleatorias, se requiere de un estatuto, aceptado generalmente, que garantice la coexistencia de lo diverso. ${ }^{30}$ La legitimidad de los derechos humanos no está determinada por su lugar de origen ni limitada por la sociedad donde fueron enunciados por vez primera; estos derechos no impiden de ninguna manera que cada individuo despliegue su potencialidad de desarrollo y, sobre todo, sus peculiaridades y singularidades en el marco de culturas muy diversas entre sí. La razón de ello reside en el hecho de que los derechos humanos no prescriben obligatoriamente cuál es el contenido específico de ese desarrollo potencial, ni cuál deberá ser la configuración definitiva de aquellas peculiaridades y ni siquiera cuál podría ser la definición substancial de una humanidad bien lograda. Los derechos humanos constituyen sólo la base (pero la base absolutamente indispensable) para que el Hombre pueda desenvolverse de acuerdo a sus propios cánones: justamente para este fin le protegen, por ejemplo, de las muy probables arremetidas de sus congéneres, de los inevitables ataques de otros grupos organizados y de las insidiosas agresiones del aparato estatal. Los derechos humanos de corte

${ }^{30}$ Otfried Höffe, "Sieben Thesen zur Anthropologie der Menschenrechte" ("Siete tesis sobre la antropología de los derechos humanos"), en Otfried Höffe (comp.), Der Mensch-ein politisches Tier? Essays zur politischen Anthropologie (El Hombre-un animal politico? Ensayos sobre antropología política), 1992, Stuttgart, Reclam, p. 192. 
universalista fundan las condiciones posibilitantes para el desenvolvimiento práctico-realista de casi todo particularismo en un mundo complejo y altamente interrelacionado como el contemporáneo. La posibilidad de ejercer uno mismo violencia es permutada por el interés de no ser víctima de la violencia ajena. Esta renuncia a la violencia constituye una reciprocidad negativa: el desistir por ambos lados a matarse, a robarse y a perjudicarse por razones religiosas o políticas, es lo que dio lugar posteriormente a los derechos a la vida y a la integridad física, a la propiedad y a la libre expresión. Independientemente de lo que cada persona considere imprescindible para la realización de su singularidad, para ello tiene que partir necesariamente de la seguridad de su integridad física: el derecho a la vida es el primero de los grandes estatutos ético-legales de índole universalista.

Por otra parte, los derechos humanos no representan una concepción estrictamente individualista y eurocéntrica del Hombre, como se ha aseverado en el ámbito islámico y en numerosos países de Asia y África. Contra la acusación del individualismo acendrado, se puede aseverar que, desde Aristóteles, se supone más bien que el ciudadano posee una naturaleza social y que su realización más o menos perfecta tiene lugar en medio de la polis y gracias a impulsos de una clara sociabi126 lidad: la convivencia con los conciudadanos enriquece la vida personal. ${ }^{31}$ Por otra parte, se puede afirmar que, si bien la concepción de los derechos humanos es de origen europeo occidental y ha sido formulada básicamente bajo la influencia de la Ilustración, constituye hoy en día un legado cultural de alcance universal, aceptado por una amplia mayoría de naciones e interiorizado paulatinamente por cada vez más individuos a nivel mundial; los derechos humanos configuran hoy el único fundamento que permite la coexistencia pacífica de los pueblos y el reconocimiento efectivo de su alteridad, es decir, de su opción por la diferencia.

A comienzos del siglo XXI, después de haber experimentado los horrores asociados a un racionalismo exclusivamente instrumentalista y a un fundamentalismo antihumanista, lo más razonable parece ser una síntesis entre principios universalistas y valores particularistas, sínte-

${ }^{31}$ Ibidem, p. 200 sq. 
sis que, por un lado, logre preservar elementos identificatorios aceptables de las tradiciones de cada pueblo y, por otro, pueda generalizar lo positivo de la civilización occidental. No hay que caer en el extremo de ver en numerosos movimientos contestatarios del Tercer Mundo -que combinan demandas socio-económicas de indudable justicia con reivindicaciones étnico-culturales- la alternativa razonable, "la resistencia o reserva íntima de todos nosotros ante el actual desarrollismo", "la nostalgia de los dioses, voluntad de respeto de la naturaleza madre", como lo hizo Abel Posse con relación a la sublevación de Chiapas (México, a partir de 1994). Según Posse, "los mayas que se rebelan hoy son hombres de la selva, capaces de conocer el vuelo de los pájaros [...] Son hombres del estar cósmico, agredidos por la prepotencia de la cultura 'occidental' del hacer". De acuerdo con este autor, los mayas se habrían mantenido hasta hoy como "hombres primigenios del ser", negándose al "hacer de los civilizados". "Son ellos, los puros, [...] los que nos demuestran un camino en medio del actual eclipse total de los valores de "nosotros', los patrones de la 'civilización".. ${ }^{32}$ Es superfluo añadir que este enfoque de reminiscencias heideggerianas proyecta sobre un movimiento violento de dudosa ideología y fines convencionales, las añoranzas culturales y ecologistas de gente cansada del sin sentido de la civilización industrial de Occidente, echando por la borda, al mismo tiempo, lo rescatable de la misma: el espíritu críticocientífico, la democracia parlamentaria y representativa, el respeto al individuo y la moral universalista.

Lo rescatable de la cultura occidental contemporánea reside en la tolerancia hacia los otros, la moderación ante los dogmatismos, el respeto de las reglas de juego, la división de poderes y la consideración de que hay algo allende los intereses propios. Todo esto, dice Dieter Senghaas, se consiguió a lo largo de un proceso civilizatorio dirigido a menudo contra la propia voluntad, las costumbres y las pretendidas esencias civilizatorias inconfundibles. ${ }^{33}$ Este saber sería el mejor legado de Euro-

${ }^{32}$ Abel Posse, "México y el teocidio maya", en La razón, del 30 de enero de 1994, La Paz, p. 6.

${ }^{33}$ Dieter Senghaas, Zivilisierung wider Willen. Der Konflikt der Kulturen mit sich selbst (La civilización contra la propia voluntad. El conflicto de las culturas consigo mismas), 2002, Frankfurt, Suhrkamp, p. 35 sq. 
pa al resto del mundo: el conflicto de las culturas consigo mismas es productivo si logra afianzar estos valores de orientación de forma más o menos permanente.

Isaiah Berlin propugnó una síntesis ejemplar para un sentido común guiado críticamente. El racionalismo de la Ilustración, los derechos individuales, las libertades políticas y la moral universalista deberían combinarse con el pluralismo cultural, el respeto de la identidad de otros pueblos y modelos civilizatorios y con el derecho a un desarrollo según parámetros más o menos propios. El resultado sería un liberalismo político incluyente de carácter normativo: de un lado, se hallarían las libertades negativas clásicas, dirigidas contra un orden y un Estado con pretensiones autoritarias, libertades aseguradas mediante estatutos legales; por otro, se encontrarían las libertades positivas, consagradas a consolidar un orden social que sea, al mismo tiempo, un hogar familiar con el que los ciudadanos puedan identificarse plenamente. Todo lo cual es mucho más fácil de enunciar que de construir en la profana realidad...

Tratar de entender lo Otro no significa exculpar sus lados obscuros y menos aun justificarlos. Un relativismo cultural de carácter radical nos haría imposible conocer y apreciar otros sistemas culturales y sociales, incluyendo su filosofía y literatura, sus obras de arte y sus ideas sobre Dios. La labor intelectual tiene que ser también el ensayo de traducir fidedignamente de una cultura a otra; la traducción es, como dijo Umberto Eco, "la metáfora de una visión tolerante del mundo". ${ }^{34}$

\footnotetext{
${ }^{34}$ Umberto Eco, "Entrevista", en El correo de la UNESCO, junio de 1993, vol. XLVI, p. 6.
} 